\title{
DESINTERESSE INTERESSADO
}

\section{Lidiane Soares Rodrigues*}

Universidade Federal de São Carlos

São Carlos - São Paulo - Brasil

Resenha do livro: BRUN, Eric. Les situationnistes. Une avant-garde totale. Paris: CNRS

Éditions, 2014, 454 p.

Em 30 de novembro de 1994, Guy Debord suicidou-se em sua casa com um só tiro no peito. Ele tinha 63 anos e uma doença incurável oriunda do consumo de álcool. Àquela altura, o animador da Internacional Situacionista (IS) amargava sua notoriedade, adquirida contra os princípios que orientaram sua produção artística e teórica.

A IS foi fundada em 1957 e autodissolvida em 1972. Inicialmente, reunia alguns pequenos grupos: a) a Internacional Letrista (IL, fundada em 1952), cujos representantes eram Guy Debord e Michèle Bernstein, sua primeira esposa; b) o Movimento Internacional por uma Bauhaus Imaginista(MIBI, fundado em 1953), cujos representantes eram AsgerJorn, Piero Simondo, Pinnot-Gallizio, Walter Olmo e Elena Verrone; c) a Associação Psicogeográficade Londres, fundada também em 1957, logo integrada à IS por seu único representante,

\footnotetext{
* Doutora pelo Programa de Pós-graduação em História Social do Departamento de História da Faculdade de Filosofia, Letras e Ciências Humanas, da Universidade de São Paulo - FFLCH/ USP. Professora do Departamento de Ciências Sociais da Universidade Federal de São Carlos. E-mail: lidianesrgues@gmail.com.
} 
Ralph Rummey. Em linhas gerais, os situacionistas entendiam que a divisão social do trabalho, a especialização das atividades que dela resulta e a decorrente cisão entre profissionais e leigos seriam superadas pela revolução. A "verdadeira revolução" colocaria fim ao reino da escassez materiale instauraria a satisfação plena do homem, tornado autêntico, para o qual seria possível "caçar de manhã, pescar à tarde, pastorear à noite e fazer crítica depois da refeição (...) sem por isso se tornar exclusivamente caçador, pescador ou crítico".

Modularam este adágio do jovem Marx em tom próprio, nutrindose de outros autores, como Johan Huizinga do Homo Ludens. Imaginavam as profissões e especializações sendo substituídas por uma nova prática: a "construção de situações", entendida como reapropriação coletiva da história humana e de todas as esferas da vida em conjunto. Elaboraram uma crítica da "representação burguesa da felicidade" e teorizaram a "vida que vale a pena ser vivida". Esta foi concebida com referência à "vida boêmia", tal qual resulta do acúmulo de gerações de vanguardas artísticas desde o final do século XIX: recusar a disciplina e a rotina, desembaraçar-se das coerções da reprodução econômica, exercitar a dimensão lúdica, viver aventuras, praticar jogos e lazeres não convencionais, criar conscientemente "situações" intervindo/testando a vida cotidiana.

A jurisdição a respeito da legitimidade deste estilo de vida depurado da degradação burguesafoi construída ao longo do percurso do movimento, variando segundo suas fases. Por um lado, elas são marcadas pela colaboração e concorrência com os representantes de diversas fontes: literárias (especialmente poética);artísticas (pintura,cinema, arquitetura e urbanismo); filosóficas (Feuerbach, Hegel, Marx - por meio de Henri Lefebvre);e político-revolucionárias (reivindicavam, particularmente, a Comuna de Paris e o comunismo de conselhos, ${ }^{1}$ discutiram muito com Argumentos, e Socialismo ou Barbárie). Se hoje obras situacionistas são evocadas em áreas as mais diversas (das artes plásticas à teoria da revolução), isso se deve a esta diversidade de interesses. Por outro lado, estas fases se caracterizam também por modificações substantivas na morfologia do grupo ede seu público. O crescimento deste último- resultante não prevista tanto de sua movimentação, indo das artes à teoria revolucionária, quanto de sua eleição a profetas em maio de 1968

\footnotetext{
${ }^{1}$ Grosso modo, grupos políticos antistalinistas, não trotskistas, que reivindicam um comunismo conduzido direta e democraticamente pela base, constituído por "conselhos de trabalhadores". Inspiram-se nas experiências da revolução alemã (derrotada em 1918-1919) e, por vezes, no levante húngaro anti-URSS (de 1956).
} 
- conduz o grupo à aporia final impeditiva da manutenção da lógica de integração construída na base do "quem perde ganha".Eis o objeto do livro de Eric Brun - Les situationnistes. Une avant-garde totale - cuja apresentação é feita a seguir.

"Quem perde ganha" era o princípio gerador das práticas, das criações estéticas e teóricas do grupo, e seu líder carismático, elo entre a IL e a IS, Guy Debord, fez-se fazendo-o.

Segundo Brun,o problema que dá origem ao "quem perde ganha", isto é, ao desinteresse interessado em ser reconhecido como desinteressado,responde à dificuldade de ser uma vanguarda autêntica nos anos 1950.Tal experimento precisava ser capaz de se proteger tanto da rotinização "pela vida burguesa vulgar e danificada" quanto da consagração que atingiram vanguardas anteriores. Eis uma das fontes da intransigência ética e do forjamento de um estilo de vida que tinha por princípio a austera recusa do sucesso. A rejeição do êxito torna-se o fiador da legitimidade do pertencimento à grade de valores do grupo. Daí, o decreto permanentedos limites"revolucionários" dos outros, animando a busca pela "ultrapassagem" politicamente radical, articulado ao comportamento contra a cultura vigente e ao risco de consagração, tornar-separa os integrantes o regramento máximo a partir da qual se julgam reciprocamente. E, obviamente, controlam-se reciprocamente. Trata-se de uma lógica do desinteresse pelo mundo -que os torna tanto mais interessados uns aos outros quanto mais a satisfação de suas demandas simbólicas depende desta libido socializada -fundada na honra de ser desprezado pelos que não pertencem ao grupo (a sociedade burguesa). Já para os aspirantes a "situs", aquela régua de radicalismo torna-se uma barreira a atravessar, posto que delimitasse o direito de ingresso no coletivo em que fracassar é ser bem-sucedido (p. 103). Os interessados em ser situs deviam dar provas de seu desinteressenas glórias mundanas, afiançar o gosto não pela arte como parte da vida, mas de exercer "a vida como arte"; e, sobretudo, entrar no jogo paroxístico das negações bem orquestradas - "a poesia só sobreviverá por meio de sua destruição" (p. 149). Por fim, parao líder, o "quem ganha perde" como princípio gerador da prática foi fonte de acumulação e monopolização do carisma, malgrélui-même. É que a dinâmica de ultrapassagem que move a integração e a desintegração dos minúsculos grupos militantes os ultrapassa.

É este modus operandi do militantismo de pequenos grupos que a pesquisa infatigável de Eric Brun disseca ao esquadrinhar o labirinto da negação do status quoe da acumulação de "capital de radicalismo", ao recuperar a lei- 
tura da sociologia da religião de Max Weber proposta por Pierre Bourdieu. ${ }^{2}$ Nada de se satisfazer, portanto, com o paralelismo fácil das posições do campo religioso no campo da cultura, tão ao gosto de um direitismo ideológico pouco diligente e zombeteiro. O “carisma (do profeta) não explica, [mas é ele que]precisa ser explicado" (p. 10).

A inteligibilidade do percurso que conduz o grupo das artes à políticapressupôs a reconstituição diacrônica e sincrônica da eleição de aliados/ adversários, assim como dos lances de cumplicidade e concorrência dela oriundos. A matéria diacrônica é o eixo da primeira parte do livro - em que o autor procura deslindar "[a]s coordenadas do posicionamento situacionista" - composta por quatro capítulos, a saber: "O envelhecimento social do surrealismo"; "Um novo pretendente à vanguarda: o letrismo"; "A internacional letrista à margem do campo literário"; "Guy Debord 'na e para além' da boemia". O "espaço de posicionamento" se constitui do conjunto de aliados/ adversários a que os agentes se reportam - isto é, com os quais se importam. Esta eleição, por sua vez, resulta de esquemas de classificação do mundo socialmente fabricados pela trajetória social dos produtores e pela história dos campos nos quais suas aspirações são investidas. Então, ao invés de partir de uma definição fixa e normativa de vanguarda, Brun recupera os conflitos para defini-la em perspectiva relacional e histórica.Ao adotar essa abordagem, ele pôde surpreender no programa dos situs o empenho em se diferenciar dos antecessores eleitos.Omovimento apresenta-se como uma vanguarda artística pela filiação reivindicada (futurismo, dadaísmo, surrealismo), pelos princípios de valorização que mobiliza e pelos instrumentos de manifestação pública que emprega. A busca por proteger-se da degradação/consagração orienta tanto o ideal da "beleza como situação" quanto a conversão do grupo em agente que se dirigirá às disputas do subcampo político dos teóricos revolucionários. Tal reorientação consiste na aposta para superar a armadilha da consagração/degradação a que os outros sucumbiram em sua posteridade.

Há muitos exemplos dessa dinâmica, destaquem-sedois. Por exemplo, a reação do jovem Debord face ao balanço do surrealismo proposto por Maurice Nadeau -antigo militante comunista, depois trotskista e frequentador de André Breton. Ele indica o padrão de exigências a que se submeteram os situs: “[a superação do surrealismo se localiza no futuro] e provavelmente em outro plano que o da arte", afinal, este movimento "antiliterário, antipoético,

2 BOURDIEU, P. Gênese e estrutura do campo religioso. In. MICELI, Sérgio (org. e trad.). A economia das trocas simbólicas. $5^{\text {a }}$ edição. São Paulo: Perspectiva, 2003. 
antiartístico só conseguiu criar uma nova literatura, uma nova poesia (...)", inferior ao que havia prometido (p. 147). Daí, face ao diagnóstico do desgaste das experimentações formais em poesia, imaginarem a proposição das "situações" como "ação direta na vida cotidiana", posto que provisórias, vividas verdadeiramente e conscientemente construídas (em oposição ao espontaneísmo surrealista). É pela elaboração de uma "retórica da negação" que Debord vai construindo "uma lógica de ultrapassagem incessante" do que for a convenção artística, e posteriormente teórica e política em vigência. Um segundo exemplo: sendo simpático à recusa de prêmios, seja Nobel seja Goncourt, isso não era suficiente. Uma vanguarda autêntica não deveria merecê-lo.

O mesmo impulso da diferenciação e ultrapassagem, surpreendido na relação diacrônica com os antecessores, orienta o grupo em direção à política. O marxismo das esquerdas revolucionárias externas e adversárias do Partido Comunista Francêsé central, obviamente. Em afinidade com os situs, o jogo eleitoral(mundano do PCF) não é, para elas, "jogo verdadeiro". Por isso,a "teoria revolucionária"converte-seem centro de sua disputa - num típico movimento de "rechaço ao mundo" - sendo mesmo a base tanto de sua integração (contra o PCF) e de sua cissiparidade em grupúsculos (processo que leva à bolsa de "valores do radicalismo"). ${ }^{3}$ Como ocorre com frequência, este marxismo depurado da vida política real é a forma por excelência que assume a tomada de posição radical entre produtores simbólicos, conformando o estoque de anti-herois legítimos e de leituras "perigosas" exigidas assim como o banco de citações rotinizadas nesse universo - cujo uso eficaz depende do habitus militante, apto a acioná-los no momento exato e de modo correto.

Assim, se da IL (1952) à IS (1956) e durante os primeiros anos desta "o espaço de posicionamento" se delineia por controvérsias em torno do título de vanguarda cultural - e sua rede internacional se compõe de pintores, críticos de arte e intermediários de galerias de vanguarda -, a partir de 1959, sempre por iniciativa de Debord, é o espaço das revistas intelectuais radicais que passa a interessar a IS. Eric Brun acompanha, por meio da correspondência privada, ${ }^{4}$ a atenção de Debord voltada à controvérsia entre Arguments

\footnotetext{
3 Dispensável dizer que os termos são utilizados pela precisão e não pelo tom pejorativo - que comprometeria qualquer análise desta experiência. Particularmente, "bolsa de valores do radicalismo" é uma ideia que Eric Brun explora a partir do seminal estudo de Philippe Gottraux sobre o grupo de Claude Lefort e Cornelius Castoriadis(GOTTRAUX, Philippe. Socialisme ou barbarie. Un engagement politique et intellectuel dans la France de l'après-guerre. Lausanne:Éditions Payot, 1997).

4 Recentemente disponibilizada no acervo da Biblioteca Nacional da França e imprescindível para algumas conclusões do trabalho em tela.
} 
e Socialisme ou Barbarie (SouB), a respeito do comportamento da classe operária - sempre menos revolucionária do que gostariam os intelectuais - assim como as suas reações e a inserção da IS neste debate. Orienta-o, é evidente, a lógica da ultrapassagem e o típico procedimento de reenviar o adversário à posição inferior, parcial e insuficientemente revolucionária. Assim, comas duas revistasposiciona-se de acordo com o diagnóstico da apatia da classe operária e,contraArguments,nega a negativa do potencial revolucionário do proletariado;discorda da proposta dos então fundadores da sociologia do trabalho (Touraine, Collinet e Crozier, que assinam a intervenção) defendendo a integração da classe operária no sistema capitalista por meio de sua participação na gestão das empresas.Inicialmente cifradas no que tange à teoria, as críticas a Arguments são explícitas e impiedosas quando esta tratar de arte. O princípio dos situsé acotovelar estabelecidos para entrar no jogo e, uma vez nele, esbofetear quando o assunto for de seu domínio. Na lógica desse espaço, a rivalidade com Arguments favorece tanto a patronagem do então renovador do marxismo francês (modo eufemizado de dizer, "divulgador de Marx a serviço da crítica do PCF"), ou seja, Henri Lefebvre, quanto a aproximação com SouB.Trata-se do ponto alto da análise: a lógica argumentativa e o princípio de criação artística (ultrapassagem/quem ganha perde) dos situs/Debord correspondem à lógica de agrupamento/ruptura e cumplicidade/concorrência,em alta rotatividade e ritmo acelerado. Assim, a aliança com Lefebvre dura um biênio, com SouB, um triênio.

Se é impossível reproduzi-la neste texto, é incontornável assinalar o êxito da poderosa chave explicativa para a cisão entre SouB e IS, e para autodissolução desta última. Trata-se de um problema que ronda o subcampo político em questão e está na origem da ginástica classificatória e da multiplicação de seus labels, fazendo da ultraesquerda um caldo de sopa de letrinhas denominando as organizações múltiplas. Ora, a afinidade de disposições, de palavras de ordem, o mesmo sistema de oposições aos vícios mundanos do PCF etc. ameaçam os pequenos grupos de indiferenciação. Como não podem se confundir com a "direita" da esquerda, diferenciar-se dela é regra. Daí as rupturas públicas, amplificando diferenças criadas a partir de divergências mínimas.

A análise da autodissolução após a consagração e o aumento de efetivos pró-situs decorrentes de maio de 1968 é uma lição de como empatia ao objeto pode trabalhar a serviço da objetivação dele.Brun constata que a lógica da ultrapassagem também entraria aí em operação: Debord desqualifica seus adeptos, rechaça a moda situ, a adesão sem análise da inteligência e sentencia: "só se não precisarmos do grupo temos direito a fazer parte dele". 
No limite, segundo "os critérios de avaliação das qualidades pessoais pouco explícitos e objetivamente controlados por Debord", "só poderia restar um neste grupo: o próprio Debord". Ao cabo de uma série de eliminações e renúncias, Debord "dá livre curso à disposição aristocrática", intensificando o desprezo por tudo e por todos a seu redor (p. 424).

Guy-Ernest Debord nasceu em 1931 em Paris, mas passou infância e adolescência nosul da França. Ele perdeu o pai precocemente, foi criado pela mãe e avó. Sua aquisição da cultura literária clássica e legítima não se deu por via familiar, mas escolar, notadamente, por manuais de feitio lansoniano. Na composição global do capital de sua família, o econômico tinha mais peso do que o cultural. Desde muito jovem fascinado pelos surrealistas e inclinado a se expressar literariamente, suas relações com a autoridade escolar vão aos poucos se constituindo de modo desviante e herético. Não há espaço para a delicada reconstituição do habitus realizada por Brun, então que seja digno de nota o seguinte achado documental. Por ocasião das provas do "baccalauréat" ele e um amigo oanunciam, como se fosse um aviso de falecimento num cartão que convidasse para o velório: "é com pesar que informamos o sucesso no bac". O potencial heurístico de uma "biografia sociológica"5 se entrevê em tudo que Brun é capaz de extrair em termos interpretativos deste registro - que não passaria de uma brincadeira para um pesquisador incauto.

Não se mensura a inovação promovida por Eric Brun quando se desconhece o estado da discussão a respeito da trajetória de Debord e deseu grupo: até então havia publicações de universitários, mas não pesquisas universitárias. Para o primeiro, a intenção explicativa mal alcançava até a simplória transferência do esquema edipiano da vida pessoal para a vida artística: tendo perdido o pai precocemente, Debord teria de matá-lo na vida simbólica - daí a "ruptura" com André Breton. Quanto ao grupo, a discussão não era muito animadora. Como na bibliografia brasileira sobre grupos e intelectuais de esquerda, explicava-se o fenômeno pela quadratura do círculo, isto é, suas intenções pelo que disseram, o que disseram pelo que pensaram, o que pensaram pelo que eram suas intenções.O raciocínio só poderia redundar num cenário idêntico ao dos estudos brasileiros sobre as esquerdas e os marxismos: o número de estudos dedicados ao grupo era o mesmo de "influências" (re)conhecidas, pois o diálogo entre os especialistas reproduzia a disputa dos

\footnotetext{
${ }^{5}$ HEILBRON, Johan. Comment penser la genèse des sciences sociales?Revue d'Histoire des Sciences Humaines, n.15, 2006/2, p. 114.Disponível em: http://www.cairn.info/revue-histoire-dessciences-humaines-2006-2-page-103.htm.
} 
agentes estudados. Pudera. Em que se pese o interesse da erudição dos radicais por estas "influências",raciocinar nestes termos consiste em se deixar dominar por disposições cognitivas forjadas na dinâmica dos debates situs - documentando novamente a experiência e renunciando à sua inteligibilidade.

A saída de Brun às leituras teleológicas e anacrônicas, às explicações tautológicas das intenções/influências não redundou no postulado do cinismo pragmático das escolhasestratégicas - pois ele sabe que esta é uma conduta, entre muitas possíveis, a rigor, a mais fácil de ser explicada. Difícil é compreender o interessesincerono desinteresse, a ação verdadeiramente orientada pelo trágico do "quem ganha perde".Esta elegante mescla de empatia e objetivação não seria tão sagaz sem uma meditada construção do problema de pesquisa. Ora, sendo os vanguardistas críticos sagazes e opositores sistemáticos do processo de diferenciação técnica/social do trabalho, como valer-se da ciência social que não rejeita esse processo por princípio, e pretende, explicando-o, dar conta das condicionantes deste rechaço em suas modalidades estéticas, intelectuais, políticas e organizacionais?

Elaborada por Pierre Bourdieu para dar conta do processo de diferenciação e especialização das atividades sociais, a teoria dos campos e o conjunto conceitual que a acompanha (habitus, campo, capital) pareciam ser desafiados por um grupo como este e por seus homólogos, posto que recusassem precisamente esta direção do mundo moderno e, para fazê-lo, tornassem-se sujeitos multiposicionais. ${ }^{6}$ Digamos que um pesquisador descuidado fosse, entretanto, encorajado a mobilizá-la para o "caso". Certamente, depois de pensar sem refletir, diria, satisfeito: "Eureka! Trata-se do campo das vanguardas!".

Na avaliação de Eric Brun, este tem sido um "uso sistemático e vulgarizado" (p. 6),responsável por um inflacionamento questionável dos "campos" e estéril para os situacionistas.Impregnado pelo espírito atrevido dos situs, Brun recusou este uso, carente de imaginação analítica e de malícia teórica.Se esta vanguarda se constitui na sucessão de oposições - às artes (diacronia/surrealismo) e aos grupos intelectuais (sincronia/Arguments, SB, Henri Lefebvre) - segundo ele, a pesquisa perderia caso se contasse com o enquadramento grosseiro do "campo das vanguardas". Por isso, ele escolheu localizá-los nas relações de "com/contra" por meio da qual se construíram.

Por tudo o que foi apresentado - e também pelo que não coube neste texto - trata-se de uma pesquisa exitosa, pelos procedimentos adotados,

\footnotetext{
${ }^{6}$ BOLTANSKI, Luc. L'espace positionnel: multiplicité des positions institutionnelles et habitus de classe.Revue Française de Sociologie, 14(1), 1973.
} 
pela laboriosaatenção à minúcia, pela exploração documental, pela reconstituição histórica e domínio pleno da teoria dos agentes que analisa, sem deixá-la se confundir com a teoria que mobiliza na sua análise. Sobretudo no que tange à construção do problema de pesquisa, tem abrangência mais ampla.As questões de método são idênticasàs de quem se dispusesse a mobilizar a teoria dos campos para analisar a produção intelectual de marxistas, as práticas de militantismo teórico, dentre outros. Por isso, vale a pena meditar a respeito delas e, torcendo pela tradução linguística do livro de Eric Brun, trabalhar por suatradução intelectual - infinitamente mais árdua e para a qual esta resenha gostaria de contribuir.

\section{Referências bibliográficas}

BOLTANSKI, Luc. L'espace positionnel: multiplicité des positions institutionnelles et habitus de classe. RevueFrançaise de Sociologie, 14(1), 1973.

BOURDIEU, Pierre. Gênese e estrutura do campo religioso. In: MICELI, Sérgio (org. e trad.). A economia das trocas simbólicas. 5a edição. São Paulo: Perspectiva, 2003.

GOTTRAUX, Philippe. Socialisme ou barbarie. Un engagement politique et intellectuel dans la France de l'après-guerre. Lausanne: Éditions Payot, 1997.

HEILBRON, Johan. Comment penser la genèse des sciences sociales?Revue d'Histoire des Sciences Humaines, n.15, 2006/2.Disponível em: http://www.cairn.info/ revue-histoire-des-sciences-humaines-2006-2-page-103.htm. 